\title{
Deciding the fate of radial arteries: Will surgeons take matters in their own hands?
}

\author{
Tomas A. Salerno, MD, ${ }^{\mathrm{a}, \mathrm{b}}$ and Alexandre Ferreira, $\mathrm{MD}^{\mathrm{c}}$
}

\footnotetext{
From the ${ }^{\mathrm{a}}$ Division of Cardiothoracic Surgery and ${ }^{\mathrm{b}}$ Dewitt-Daughtry Department of Surgery, and ${ }^{\mathrm{c}}$ Division of Cardiology, Jackson Memorial Hospital and the University of Miami Miller School of Medicine, Miami, Fla. Disclosures: Authors have nothing to disclose with regard to commercial support.

Received for publication June 10, 2018; revisions received June 10, 2018; accepted for publication June 11, 2018; available ahead of print Aug 8, 2018.

Address for reprints: Tomas A. Salerno, MD, Jackson Memorial Hospital and the University of Miami Miller School of Medicine, 1611 NW 12th Ave, Miami, FL 33136 (E-mail: tsalerno@med.miami.edu).

J Thorac Cardiovasc Surg 2019;157:576-7

$0022-5223 / \$ 36.00$

Copyright (c) 2018 by The American Association for Thoracic Surgery

https://doi.org/10.1016/j.jtcvs.2018.06.039
}

The introduction of the left internal thoracic artery (ITA) to the left anterior descending artery by Loop and colleagues ${ }^{1}$ represented a major advance in coronary artery surgery. The survival advantage afforded by an ITA graft compared with a venous conduit, particularly in diabetic patients, is uncontroversial, ${ }^{2}$ and enhanced clinical outcome has been attributed to the long-term patency of this arterial graft.

The logical next step was to assume that complete arterial revascularization would favorably affect outcomes by reducing rates of repeat revascularization, myocardial infarction, and possibly mortality. Despite lack of randomized clinical trials, professional societies were quick to endorse multiple arterial grafts, supported only by a plausible biological mechanism and limited observational studies. Despite this, complete arterial revascularization has not been widely adopted. In the United States, less than $10 \%$ of coronary surgical procedures use more than 1 arterial graft. ${ }^{3}$ The use of a radial artery (RA) graft is even less prevalent, and although reasons may abound, it reinforces the maxim that "those who sleep are also hard at work," as inactions also drive outcome.

More recently, Taggart and colleagues, ${ }^{4}$ in an interim analysis of the Arterial Revascularization Trial (ART) 5-year outcome, found no significant differences in clinical outcomes between patients who received a single ITA and patients who received a double ITA. Although the authors acknowledged several limitations of their study, the message of "no difference" was quick to spread, giving scientific substantiation for further reduction in the use of bilateral ITA grafts.

Analysis of ART indicates the possibility that technical issues, such as the use of pedicled bilateral ITA grafts in $49 \%$ of the patients, rather than skeletonized ITA grafts, may account for increased sternal wound complications. Of note, $20 \%$ of the patients with a single ITA in ART also received RA grafts. Subgroup analysis of those patients demonstrated numerically better outcome in patients with

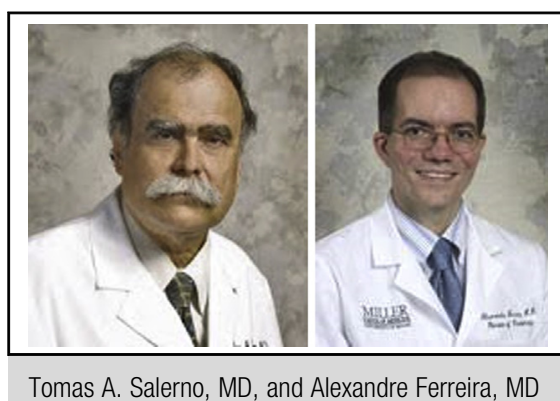

\begin{abstract}
Central Message
The RA is another conduit that can be used to achieve complete arterial revascularization. Preserving the structural integrity of this peculiar conduit, particularly because of its unique biology and vulnerability to vessel wall ischemia, vasospasm, and endothelial injury, is paramount. Elevating the RA to the post of second favorite conduit in surgical revascularization will have implications for interventional cardiologists, as refinements in coronary angiography and intervention are quickly turning radial access into the default strategy. The heart team approach may have yet another role to play in deciding the fate of the RA. This time, team work must start before coronary angiography is performed.
\end{abstract}

See Article page 573
ITA grafts when RA grafts were used instead of venous grafts. Further, considering that patients with bilateral ITA also receive venous grafts, it is possible that cardiovascular events may have been related to venous graft attrition rather than the benefit of bilateral ITA. This raises the intriguing question that the real comparative trial should be complete arterial revascularizations versus a hybrid left ITA plus venous conduits.

Performing complete revascularization with all arterial conduits will invariably imply using 1 RA or both RAs. Harvesting RAs will raise a number of clinical questions, including the best harvesting technique, potential hand morbidity, and yet another turf battle with the cardiologist, this time over the best use for the RA for access or conduit.

In the current issue of the Journal, An and colleagues ${ }^{5}$ summarize current knowledge about the use of the RA compared with venous bypasses, providing evidence of superiority for the RA. Correctly, the authors comment on 
the changes that occur in any artery subjected to percutaneous intervention, such as coronary artery or RA. Therefore, it is important to draw caution to the RA access for percutaneous coronary angiography or intervention should that artery be used in the future for surgical revascularization, because it might have sustained serious intimal damage. It is well known that catheter manipulation of RA damages the endothelium. ${ }^{6}$ This may jeopardize long-term patency and could render those vessels unusable as adequate bypass conduits.

The debate over the fate of the RA will be a protracted one. RA catheterization access has been associated with less complications, enhanced patient satisfaction, and lower cost. Although interventional cardiologists in the United States have been slow to systematically adopt the RA approach, this could rapidly change if, as it is being proposed, radial procedures are reimbursed at higher rates.

Finally, cardiologists have been mindful of maintaining patency of the RA. Patent hemostasis has reduced the rate of postprocedural RA occlusion from $12 \%$ to less than $1.1 \%{ }^{7}$ Hand morbidity has been associated with loss of patency postcatheterization. Therefore, selection of patients for RA bypass is paramount. Those patients with certain skills, such as piano players, surgeons, and others, might be hesitant to have their RA removed. Despite this, surgeons perform this procedure routinely in patients. Yet, I wonder how many of those surgeons would have their own RA removed, in other words, "taking matters in their own hands."

\section{References}

1. Loop FD, Spampinato N, Cheanvechai C, Effler DB. The free internal mammary artery bypass graft: use of the IMA in the aorto-to-coronary artery position. Ann Thorac Surg. 1973; 15:50-5.

2. Yusuf S, Zucker D, Peduzzi P, Fisher LD, Takaro T, Kennedy JW, et al Effect of coronary artery bypass graft surgery on survival: overview of 10-year results from randomised trials by the coronary artery bypass graft surgery trialists collaboration. Lancet. 1994;344:563-70.

3. ElBardissi AW, Aranki SF, Sheng S, O'Brien SM, Greenberg CC, Gammie JS. Trends in isolated coronary bypass grafting: an analysis of the STS adult cardiac surgery database. J Thorac Cardiovasc Surg. 2012;143:273-81.

4. Taggart DP, Altman DG, Gray AM, Lees B, Gerry S, Benedetto U, et al Randomized trial of bilateral versus single internal-thoracic-artery grafts. N Engl J Med. 2016;375:2540-9.

5. An KR, Tam DY, Gaudino MFL, Fremes SE. Radial arteries for coronary angiography and coronary artery bypass surgery: are two arteries enough? J Thorac Cardiovasc Surg. 2019;157:573-5.

6. McGregor M, Sheldon H, Dwyer D, et al. The role of intimal hyperplasia in arterial spasm. Can Med Assoc J. 1984;131:329-30.

7. Cubero JM, Lombardo J, Pedrosa C, Diaz-Bejarano D, Sanchez B, Fernandez V et al. Radial compression guided by mean artery compression versus standard compression with a pneumatic device. Catheter Cardiovasc Interv. 2009;73: 467-72. 